\title{
Production Relocation and the Effect of Monetary Policy
}

\author{
Hiroyuki Nishiyama \\ Kinki University
}

\begin{abstract}
This paper analyzes the macroeconomic effect of production relocation by using an open economy macroeconomic model. Our analysis shows, paradoxically, that acceleration in production relocation might have an expansive effect on the home economy. We also show that monetary expansion has welfare-enhancing effects even in an economy where production relocation exists. However, advancing production relocation amplifies the effect of monetary policy on the exchange rate. On the other hand, it reduces the effect on the relative home income by advancing production relocation.
\end{abstract}

- JEL Classification: F23, F41, F42

- Key words: Monetary policy, Production relocation, Hollowing out, Beggarthy-neighbor

\section{Introduction}

Recently, a large number of Japanese firms have shifted their production location abroad, especially to China most recently. Hence, many economists and policy makers worry about the "hollowing out" of Japanese industry.

According to the conventional wisdom, production relocation substitutes for domestic investment in plant and machinery; therefore, it is certainly regarded as the main factor of the "hollowing out" of domestic industry. However, for instance, the Japanese economy experienced an unprecedented boom in the second half of

*Corresponding address: Hiroyuki Nishiyama: School of Economics, Kinki University, 3-4-1, Kowakae, Higashi-Osaka, Osaka 577-8502, Japan. Tel.:+81-6-6721-2332; Fax.: +81-6-6729-2493; E-mail: nishiyama @eco.kindai.ac.jp.

(C2005-Center for International Economics, Sejong Institution, All Rights Reserved. 
the 1980's in spite of an increase in foreign direct investment (and production relocation). More recently, Japanese export of intermediate products (steel, aluminum etc.) to China is increasing as Japanese multinational enterprises (MNEs) advance their production relocation to China. Moreover, the economy of Taiwan experienced long-run growth until recently, despite accelerating production relocation. How should we regard these phenomena? ${ }^{1}$ As well, how should the government respond to the situation, in case production relocation affects the domestic economy in a deflationary way?

In recent years, some Japanese economists have asserted the effectiveness of the depreciation strategy (of Japanese Yen) as a way to escape from Japan's economic stagnation. Certainly, it seems that depreciation of Yen is an effective measure to re-vitalize the Japanese economy through an expansion of Japanese exports. ${ }^{2}$ However, if many of the domestic production processes are relocated abroad, the depreciation of the currency may not aid in the expansion of exports. In addition, we should note that this depreciation strategy (, which contains the macroeconomic policy that induces depreciation,) might be rejected by foreign governments, because it is believed that this policy may become a beggar-thy-neighbor policy.

According to the standard theoretical inference of the beggar-thy-neighbor problem presented by the Mundell-Fleming-Dornbusch model, a country benefits from depreciation of their currency (and expansion of their exports), but other countries suffer. On the other hand, Obstfeld and Rogoff $(1995,1996)$ point out that a macroeconomic policy that induces the depreciation of domestic currency is equally beneficial to all countries. ${ }^{3}$

The main purpose of this paper is to make clear the impact of the existence of production relocation on macroeconomy. Specifically, we will focus on whether the shift of production location affects the efficacy of macroeconomic policy.

The paper is organized as follows: In section 2 we construct a two-country macroeconomic model that contains the production relocation mechanism. The

\footnotetext{
${ }^{1}$ Despite that the impact of production relocation has already been recognized, all but a few theoretical analyses of MNEs or FDI concern trade theory. For instance, Markusen and Maskus (2001) is an up to date survey.

${ }^{2}$ Many empirical studies have noticed the degree of exchange rate pass-through to prices. See, for instance, Goldberg and Knetter (1997).

${ }^{3}$ Tille (2001) presents a more generalized model that focuses on the intermediaries, and shows the possibility that monetary expansion causes either a beggar-thy-neighbor/prosper-thyself or a beggarthyself/prosper-thy-neighbor effect.
} 
structure of the model is based on Obstfeld and Rogoff (1995), but ours is a static version of their model. Section 3 examines the effects of production relocation on national economies, and we show that the conventional wisdom doesn't always hold true. Section 4 examines the effects of monetary expansion in home and foreign countries, and in Section 5, we examine the efficacy of monetary expansion in the economy where some home firms relocate their production location to abroad. As a result, we find that the monetary expansion in any country becomes a prosper-thyself/prosper-thy-neighbor policy in our model. However, advancing production relocation amplifies the effect of monetary policy on the exchange rate (terms of trade). On the other hand, it reduces the effect on "relative" home income by advancing production relocation. Finally, the last section provides some concluding remarks.

\section{The Model}

We assume a world of two countries, Home (H) and Foreign (F). The representative household in each country consumes goods indexed by interval $[0,1]$. The utility function of the household in country $\mathrm{H}$ is written as follows:

$$
u=s \ln L+(1-s) \ln C, \quad 0<s<1,
$$

where $C=\left[\int_{0}^{1}\left(c_{i}\right)^{\rho} d i\right]^{\frac{1}{\rho}}(0<\rho<1) . L$ is the money demand, $c_{i}$ is the consumption of goods $i$, and $C$ is the aggregate consumption.

The household solves their utility maximization subject to the budget constraint:

$$
L+C=\frac{M_{0}}{P}+\tau+z
$$

The government budget constraint in country $\mathrm{H}$ is $\tau=\left(M-M_{0}\right) / P$. We now have the following demand functions:

$$
L=s\left(\frac{M}{P}+z\right), C=(1-s)\left(\frac{M}{P}+z\right), c_{i}=\left(\frac{p_{i}}{P}\right)^{\frac{1}{\rho-1}} C, \quad(3 \mathrm{a}, \mathrm{b}, \mathrm{c})
$$

where $P=\left[\int_{0}^{1}\left(p_{i}\right)^{\frac{\rho}{\rho-1}} d i\right]^{\frac{\rho-1}{\rho}} . P$ is the price index of $p_{i}, M$ is the nominal money supply, $M_{o}$ is the money holding at the beginning of period, $\tau$ is the transfer from the government, and $z$ is the real national income. We assume that the behavior of 
the foreign household is the same as that of the home household.

The goods indexed by interval $[\alpha, 1]$ are produced in country $\mathrm{H}$, and the rest of the goods $(i \in[0, \alpha])$ are produced in country $\mathrm{F}$. We assume that the goods indexed by $[\beta, 1]$ are produced by home firms, and the goods indexed by $[0, \beta]$ are produced by foreign firms $(0<\beta<\alpha<1)$. Note that, under these assumptions, the goods of interval $[\beta, \alpha]$ are produced by the home multinational enterprises (MNEs) located in country F.

The profit function of the firm, which produces goods $i$ in country $\mathrm{H}$, is given by

$$
\pi_{i}=p_{i} c_{i}+e p_{i}^{*} c_{i}^{*}-w l_{i}, \quad i \in[\alpha, 1]
$$

where, asterisks denote foreign variables. We assume that labor is the only input used to produce goods, with its amount given as simply $l_{i}=c_{i}+c_{i}^{*}$. Each firm takes the wage rate as a given, choosing the optimal price level. ${ }^{4}$

$$
p_{i}=\frac{w}{\rho} \equiv p_{H}, \quad p_{i}^{*}=\frac{w}{e \rho} \equiv p_{H}^{*}, i \in[\alpha, 1] .
$$

We assume that all firms in country F strive similarly to maximize profit, and we have

$$
p_{i}=\frac{e w^{*}}{\rho} \equiv p_{F}, \quad p_{i}^{*}=\frac{w^{*}}{\rho} \equiv p_{F}^{*}, i \in[0, \alpha]
$$

The subscripts $H$ and $F$ in (5a) - (5d) show the country where the goods are produced. For instance, $p_{H}^{*}$ is the price of goods produced by the firms in country $\mathrm{H}$ and are sold in country $\mathrm{F}$.

Substituting (5a) - (5d) into the price indexes, and we obtain

$$
P=p_{H}\left[(\varepsilon)^{\frac{\rho}{\rho-1}} \alpha+(1-\alpha)\right]^{\frac{\rho-1}{\rho}}, \quad P^{*}=p_{F}^{*}\left[\alpha+\left(\frac{1}{\varepsilon}\right)^{\frac{\rho}{\rho-1}}(1-\alpha)\right]^{\frac{\rho-1}{\rho}}
$$

where $\varepsilon \equiv e p_{F}^{*} / p_{H}$ and $e$ is the nominal exchange rate. Therefore, we derive that $P$ $=e P^{*}$, which describes the expression of purchasing power parity. ${ }^{5}$

\footnotetext{
${ }^{4}$ Concerning the assumption of the nominal wage rigidity, see Appendix.

${ }^{5}$ In the presence of a "producerís currency pricing (PCP)", PPP comes into existence. However, we assume a "pricing-to-market (PTM)" behavior, PPP doesn't come into existence. See, for instance, Betts and Devereux $(1996,2000)$.
} 
The equilibrium conditions of the money market and goods market are shown as

$$
\frac{M}{P}=L, \frac{M^{*}}{P^{*}}=L^{*}, y=\gamma\left(C+C^{*}\right), \quad y^{*}=(1-\gamma)\left(C+C^{*}\right) . \quad(7 \mathrm{a}, \mathrm{b} ; 8 \mathrm{a}, \mathrm{b})
$$

where $y \equiv p_{H} Y / P, y^{*} \equiv p_{F}^{*} Y^{*} / P^{*}$, and $\gamma$ is the propensity to spend the goods produced in country $\mathrm{H}$, which is shown as

$$
\gamma \equiv(1-\alpha)\left(\frac{p_{H}}{P}\right)^{\frac{\rho}{\rho-1}}=(1-\alpha)\left[(\varepsilon)^{\frac{\rho}{\rho-1}} \alpha+(1-\alpha)\right]^{-1} \text {. }
$$

We now define that $p \equiv P / p_{H}, p^{*} \equiv P^{*} / p_{F}^{*}, m \equiv M / p_{H}, m^{*} \equiv M^{*} / p_{F}^{*}$. Using (3a), (3b), and foreign counterparts, $(6 a, b),(7 a, b),(8 a, b)$ are then rewritten as

$$
\begin{aligned}
& p=\left[(\varepsilon)^{\frac{\rho}{\rho-1}} \alpha+(1-\alpha)\right]^{\frac{\rho-1}{\rho}}, \quad p^{*}=\left[\alpha+\left(\frac{1}{\varepsilon}\right)^{\frac{\rho}{\rho-1}}(1-\alpha)\right]^{\frac{\rho-1}{\rho}}, \quad(10 \mathrm{a}, \mathrm{b}) \\
& \frac{m}{p}=\left(\frac{s}{1-s}\right) z, \frac{m^{*}}{p^{*}}=\left(\frac{s}{1-s}\right) z^{*}, \\
& y=\gamma(1-s)\left[\left(\frac{m}{p}+z\right)+\left(\frac{m^{*}}{p^{*}}+z^{*}\right)\right], y^{*}=(1-\gamma)(1-s)\left[\left(\frac{m}{p}+z\right)+\left(\frac{m^{*}}{p^{*}}+z^{*}\right)\right],
\end{aligned}
$$

$(10 \mathrm{e}, \mathrm{f})$

We now assume that the MNEs remit all of their profits to country $\mathrm{H}$, and the real national incomes are then given by

$$
z=y+\theta y^{*}, \quad z^{*}=y^{*}-\theta y^{*}
$$

where $\theta \equiv(1-\rho)\left(1-\frac{\beta}{\alpha}\right)$. We can easily find that $0<\theta<1$. The system $(10 a)-$ (10h) gives seven unknowns $\left(p, p^{*}, \varepsilon, y, y^{*}, z, z^{*}\right)$. One equation is redundant by Walras' law.

Using (9), (10a) - (10e), (10g), (10h), and the definition of $\theta$, we derive the following market equilibrium conditions.

- Money market equilibrium (AA schedule):

$$
\frac{m}{p(\varepsilon ; \alpha)}=\left(\frac{s}{1-s}\right) z, \quad p_{\varepsilon}>0
$$


- Goods market equilibrium (DD schedule):

$$
z=\{1-1-(\gamma(\varepsilon ; \alpha))(1-\theta(\alpha))\}\left(\frac{1-s}{s}\right)\left(\frac{m+\varepsilon m^{*}}{p(\varepsilon ; \alpha)}\right), \gamma_{\varepsilon}>0, \gamma_{\alpha}<0, \theta_{\alpha}>0
$$

Note that the sign of $p_{\alpha}$ can't be strictly determined. From the differentiation of (10a) and (10b), we can find the following relationships:

$$
\left\{\begin{array}{l}
\varepsilon<1 \leftrightarrow p_{\alpha}<0, p_{\alpha}^{*}<0, \\
\varepsilon \geq 1 \leftrightarrow p_{\alpha} \geq 0, p_{\alpha}^{*} \geq 0 .
\end{array}\right.
$$

However, $\varepsilon \geq 1$ isn't plausible in our model; if the price of domestic goods is less than or equal to that of foreign goods, firms will have no incentive to relocated their production location abroad. Therefore, in section 3, we examine only in the case that $\varepsilon<1$.

By differentiating (11a) and (11b), we obtain the Jacobian $(J)$ of this system:

$$
J \equiv\left(\begin{array}{cc}
-\frac{m p_{\varepsilon}}{p^{2}} & -\frac{s}{1-s} \\
A & -1
\end{array}\right),
$$

where

$$
A \equiv\left(\frac{1-s}{s}\right)\left[(1-\theta) \gamma_{\varepsilon}\left(\frac{m+\varepsilon m^{*}}{p}\right)-\{1-(1-\gamma)(1-\theta)\}\left\{\left(\frac{m p_{\varepsilon}}{p^{2}}\right)-\left(\frac{m^{*}}{p}\right)\left(1-\frac{\varepsilon p_{\varepsilon}}{p}\right)\right\}\right],
$$

and the sign of this can't be strictly determined. However, the sign of Jacobian determinant $(\Delta)$ is strictly positive:

$$
\begin{aligned}
\Delta & \equiv(1-\theta) \gamma_{\varepsilon}\left(\frac{m+\varepsilon m^{*}}{p}\right)+(1-\gamma)(1-\theta)\left(\frac{m p_{\varepsilon}}{p^{2}}\right) \\
& +\{1-(1-\gamma)(1-\theta)\}\left(\frac{m^{*}}{p}\right)\left(1-\frac{\varepsilon p_{\varepsilon}}{p}\right)>0,
\end{aligned}
$$

As the trace $J \equiv-\frac{m p_{\varepsilon}}{p^{2}}-1<0$, the stability conditions of this system are satisfied.

The short-run equilibrium of the home economy occurs at point 0 in both figures 1.1 and 1.2, where the goods market and money market simultaneous clear. The 
Figure 1.1. The short-run equilibrium of the home economy $(A>0)$

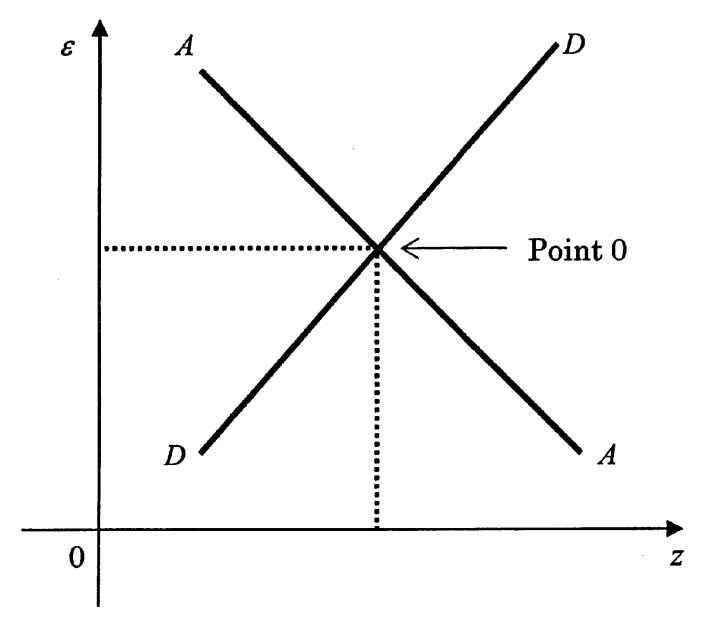

Figure 1.2. The short-run equilibrium of the home economy $(A<0)$

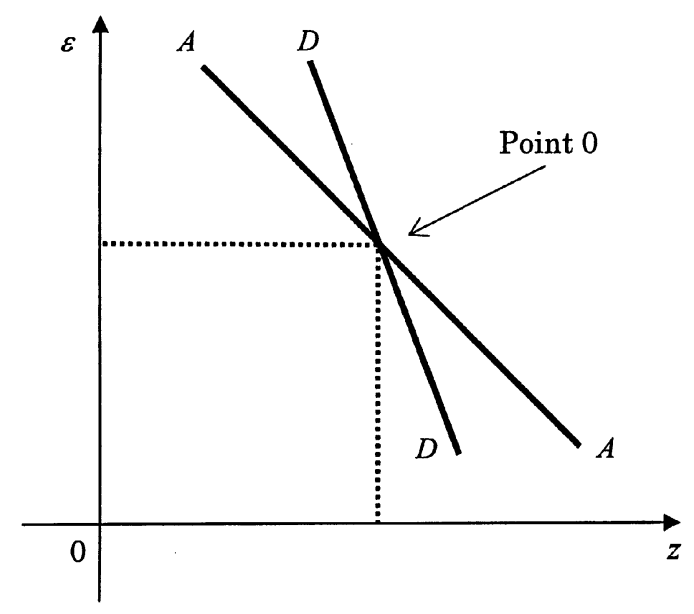

equilibrium points of the money market are summarized by the AA schedule (equation (11a)) and those of the goods market are summarized by the DD schedule (equation (11b)).

An increase in the domestic real national income ( $z$ ) causes a rise in the money demand, hence, all else equal, domestic currency must appreciate to maintain the money market equilibrium. The AA schedule therefore has a negative slope, as shown in both figures. On the other hand, the slope of DD schedule can be either positive or negative. The reason is as follows. Domestic currency depreciation (a rise in $\varepsilon$ ) has expansionary effect on domestic real national income $(z)$. A rise in $\varepsilon$ 
increases $z$ by raising the level of propensity to spend $(\gamma)$ and reducing foreign price level $\left(p^{*}\right) .{ }^{6}$ However, domestic currency depreciation also has a contractionary effect on $z$ by raising domestic price level.

If the expansionary effects through each increase in $\gamma$ or decrease in $p^{*}$ (or the combined effect) is stronger than the contractionary effect, the sign of $A$ is positive and the DD schedule has a positive slope (Figure 1.1). On the other hand, when the contractionary effect is stronger than the combined effect of the two expansionary effects, the sign of $A$ is negative and the DD schedule has a negative slope (Figure $1.2)$.

\section{Does production relocation always affect the home economy deflation?}

In this section, we regard an increase in $\alpha$ as the advance of production relocation, and examine its effect on $z$ and $\varepsilon$ by using (11a) and (11b). The results of comparative statics are shown as below:

$$
\frac{d \varepsilon}{d \alpha}=-\left(\frac{1}{\Delta}\right)\left\{\frac{m p_{\alpha}}{p^{2}}+\left(\frac{s}{1-s}\right) B\right\}, \frac{d z}{d \alpha}=\left(\frac{1}{\Delta}\right)\left\{\left(\frac{m p_{\varepsilon}}{p^{2}}\right) B-\left(\frac{m p_{\alpha}}{p^{2}}\right) A\right\},
$$

where,

$$
B \equiv\left(\frac{1-s}{s}\right)\left(\frac{m+\varepsilon m^{*}}{p}\right)\left[(1-\theta) \gamma_{\alpha}+(1-\gamma) \theta_{\alpha}-\{1-(1-\gamma)(1-\theta)\}\left(\frac{p_{\alpha}}{p}\right)\right] .
$$

The sign of $B$ can't be determined. The results of (14a) and (14b) can be arranged as follows:

- Case $1(A>0)$ :

(a) if $B>0$, the sign of $\mathrm{d} \varepsilon / \mathrm{d} \alpha$ can be either positive or negative, but $d z / d \alpha>0$.

(b) if $B<0, d \varepsilon / d \alpha>0$, but the sign of $d z / d \alpha$ can be either positive or negative.

- Case $2(A<0)$ :

(a) if $B>0$, the sign of both $d \varepsilon / d \alpha$ and $d z / d \alpha$ can be either positive or negative.

(b) if $B<0, d \varepsilon / d \alpha>0$ and $d z / d \alpha<0$.

${ }^{6}$ Reduction of $p^{*}$ stimulates the consumption of foreign households $\left(c^{*}\right)$. A part of $c^{*}$ contains the demand for the goods produced in the home country. Therefore, domestic production and domestic national income $(z)$ increase. 
In case 1-(a), we have the paradoxical result that the advance of production relocation has an expansive effect on the home country. Moreover, we should notice that there is a possibility of having this paradoxical result also in cases 1-(b) and 2-(a).

We now interpret these results intuitively. From (11a), we can see that the advance of production relocation affects the money market only by the price variation. In case of $p_{\alpha}<0$, this effect is shown as the right-side shift of AA schedule in both cases (Cases 1 and 2).

From (11b), we can find that the advance of production relocation affects the goods market through three channels. First, the advance of production relocation

Figure 2.1. Effects of production relocation (Case 1)

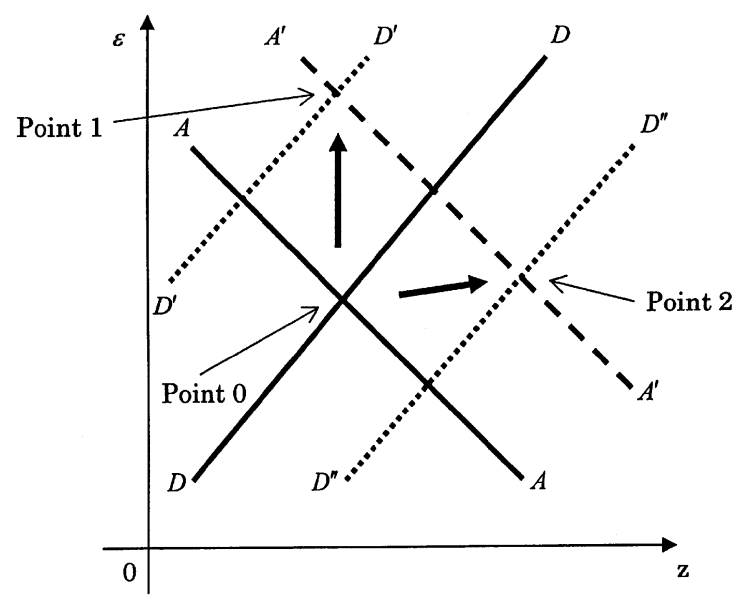

Figure 2.2. Effects of production relocation (Case 2)

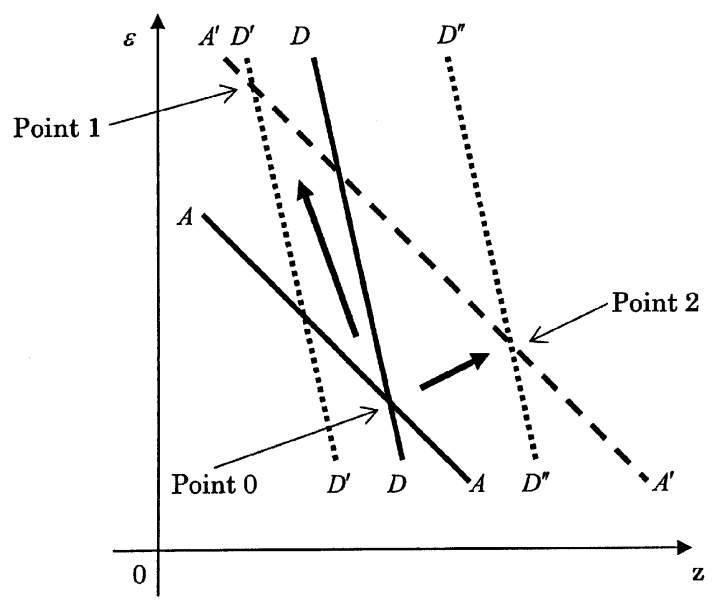


decreases the national income by reducing the propensity to spend, $\gamma($ expenditureswitching-effect). This effect is shown as the shift of DD schedule to the left in both cases (Cases 1 and 2). Second, the advance of production relocation increases the national income by reducing prices $\left(p, p^{*}\right)$ in case of $p_{\alpha}<0$ (price-effect). Finally, the spread of production relocation increases the national income by an increase in remittance from MNEs (investment-income-effect). Both price-effect and investment-income-effect are shown as the right-side shift of DD schedule in either case.

If the expenditure-switching-effect is stronger than the combination of priceeffect and the investment-income-effect, our short-run equilibrium shifts from point 0 to point 1 in both figures. On the other hand, when either the price-effect or the investment-income-effect (or the combined effect) is stronger than the expenditureswitching-effect, the equilibrium shifts to point 2 in both figures. Therefore we have the following proposition.

Proposition 1: Contrary to the conventional wisdom, the advance of production relocation doesn't necessarily have a contractionary effect on the home country, and may have an expansive effect. Especially, if either the price-effect or the investment-income-effect (or the combined effect) is stronger than the expenditureswitching-effect, we must have the paradoxical result that the advance of production relocation increases the home national income in the case that DD schedule has a positive slope.

\section{The Effect of Monetary Policy}

In this section, we examine the effect of monetary expansion. ${ }^{7}$ Totally differentiating (11a) and (11b) and using standard procedures, we have

$$
\begin{gathered}
\frac{d \varepsilon}{d m}=\left(\frac{1}{\Delta}\right)\left(\frac{1}{p}\right)(1-\gamma)(1-\theta)>0, \\
\frac{d z}{d m}=\left(\frac{1}{\Delta}\right)\left(\frac{1}{p}\right)\left(\frac{1-s}{s}\right)\left[(1-\theta) \gamma_{\varepsilon}\left(\frac{m+\varepsilon m^{*}}{p}\right)\right. \\
\left.+\{1-(1-\gamma)(1-\theta)\}\left(\frac{m^{*}}{p}\right)\left(1-\frac{\varepsilon p_{\varepsilon}}{p}\right)\right]>0 .
\end{gathered}
$$

\footnotetext{
${ }^{7}$ We can easily examine the fiscal policy effect by imposing a slight modification of our model, according to the Obstfeld and Rogoff (1995) settings.
} 
The monetary expansion in country $\mathrm{H}$ stimulates the home consumption demand, and increase domestic production. Moreover, an increase in $m$ in the home money market raises the level of $\varepsilon(e)$. The rise in the level of $\varepsilon$ increases the world consumption demand of the domestic commodity, and the level of $\gamma$ rises (see (9)). The rise in the level of $\varepsilon$ also decreases the level of $p^{*}$, hence the consumption demand in country $\mathrm{F}$ increases. In our model, a part of the foreign consumption demand contains the demand for the goods produced in country $\mathrm{H}$. Therefore, an increase in the foreign consumption demand leads an increase in production and national income level $(z)$ in country $\mathrm{H}$. On the other hand, the rise in the level of $p$ (because of the rise in $\varepsilon$ ) decreases the consumption demand in country $\mathrm{H}$. However, the sum of these effects certainly increases the ultimate national income level of country $\mathrm{H}$.

The effects of monetary expansion in foreign country on country $\mathrm{H}$ are shown as

$$
\begin{gathered}
\frac{d \varepsilon}{d m^{*}}=-\left(\frac{1}{\Delta}\right)\left(\frac{\varepsilon}{p}\right)\{1-(1-\gamma)(1-\theta)\}<0, \\
\frac{d z}{d m^{*}}=\left(\frac{1}{\Delta}\right)\left(\frac{\varepsilon}{p}\right)\left(\frac{1-s}{s}\right)\{1-(1-\gamma)(1-\theta)\}\left(\frac{m p_{\varepsilon}}{p^{2}}\right)>0 .
\end{gathered}
$$

An increase in $m^{*}$ stimulates the foreign consumption demand. As we noted above, part of the foreign consumption demand contains the demand for goods produced in country $\mathrm{H}$ in our model; therefore, both the home production and national income levels increase.

The effects of monetary expansion on the foreign economy can be considered the same as that on the home economy; therefore, we introduce only the results of our comparative statics. ${ }^{8}$ Moreover, the effects of monetary expansion on the terms of trade have already been explained. Hence we show only the effects on the foreign national income:

$$
\frac{d z^{*}}{d m}=-\left(\frac{1}{\Delta^{*}}\right)\left(\frac{1}{p^{*}}\right)(1-\gamma)(1-\theta)\left(\frac{1-s}{s}\right)\left(\frac{m^{*} p_{\varepsilon}^{*}}{p^{* 2}}\right)>0
$$

\footnotetext{
${ }^{8}$ Using (10a) - (10d), (10f) - (10h), we obtain the money and goods market equilibrium conditions in country F. Totally differentiating these conditions and using the standard procedure, we can derive (16a) and (16b).
} 


$$
\frac{d z^{*}}{d m^{*}}=\left(\frac{1}{\Delta^{*}}\right)\left(\frac{1}{p^{*}}\right)\left(\frac{1-s}{s}\right)\left[(1-\theta) \gamma_{\varepsilon}\left(\frac{m+\varepsilon m^{*}}{\varepsilon p^{*}}\right)+(1-\gamma)(1-\theta)\left(\frac{m}{\varepsilon p^{*}}\right)\left(\frac{1}{\varepsilon}+\frac{p_{\varepsilon}^{*}}{p^{*}}\right)\right]>0
$$

where

$$
\begin{gathered}
\Delta^{*} \equiv(1-\theta) \gamma_{\varepsilon}\left(\frac{m+\varepsilon m^{*}}{\varepsilon p^{*}}\right)-\{1-(1-\gamma)(1-\theta)\}\left(\frac{m^{*} p_{\varepsilon}^{*}}{p^{* 2}}\right) \\
+(1-\gamma)(1-\theta)\left(\frac{m}{\varepsilon p^{*}}\right)\left(\frac{1}{\varepsilon}+\frac{p_{\varepsilon}^{*}}{p^{*}}\right)>0
\end{gathered}
$$

Monetary expansion in country $\mathrm{F}$ also increases the national incomes in both countries in our model.

We now examine the welfare effect of the monetary expansion. Using (1), (3a), (3b), (10c), (10d), and the government budget constraint, we have

$$
\frac{d u}{d x}=\left(\frac{1}{z}\right)\left(\frac{d z}{d x}\right)>0, \quad \frac{d u^{*}}{d x}=\left(\frac{1}{z^{*}}\right)\left(\frac{d z^{*}}{d x}\right)>0,
$$

where $x=m, m^{*}$. From $(17 \mathrm{a}, \mathrm{b})$, we find that the monetary expansion in any country certainly improves the welfare of all countries. Therefore,

Proposition 2: The inference of Obstfeld and Rogoff (1995, 1996), which holds that monetary expansion becomes a welfare-enhancing policy for all countries (a prosper-thyself / prosper-thy-neighbor policy), is robustly held, in spite of our modification of introduced production relocation.

\section{Production Relocation and the Efficacy of Money Policy}

Now, we have arrived at the next question, whether the efficacy of the monetary policy varies or not as the acceleration of production relocation.

First, we solve the system (10a) - (10h) by linear-approximation around the initial equilibrium. ${ }^{9}$ Let $\hat{x} \equiv d x / \bar{x}$ for any variable $x$, where $-(\bar{x})$ shows the initial (zero-shock) equilibrium value. Using (9) and the linearized version of (10a) -

${ }^{9}$ See Obstfeld and Rogoff $(1995,1996)$. 
(10e), (10g), (10h), we have the following equations:

The $M M$ schedule: $\quad \hat{\varepsilon}=\left(\hat{m}-\hat{m}^{*}\right)-\left(\hat{z}-\hat{z}^{*}\right)$,

The $G^{\alpha} G^{\alpha}$ schedule: $\hat{\varepsilon}=\left(\frac{1-\rho}{\rho}\right)\left(\frac{\bar{y}+\theta \bar{y}^{*}}{\bar{y}}\right)\left(\hat{z}-\hat{z}^{*}\right)$,

where the sign of coefficient of $\left(\hat{z}-\hat{z}^{*}\right)$ in (18b) is positive.

We should note that, if all of the home firms produce their goods only in country $\mathrm{H}$ (, in other words, production relocation doesn't exist), the parameter $\alpha$ is equal to $\beta$. In this case, $(18 \mathrm{~b})$ is accommodated as

The $G^{\beta} G^{\beta}$ schedule: $\hat{\varepsilon}=\left(\frac{1-\rho}{\rho}\right)\left(\hat{z}-\hat{z}^{*}\right)$.

However, the $M M$ schedule doesn't change at all.

Figure 3 illustrates the effect of the money supply shock (rise in the relative home money supply; $\hat{m}-\hat{m}^{*}$ ). The $M M$ schedule shows the relationship between the change of relative national income and change in the nominal exchange rate (terms of trade). The relative national income changes affect the level of the exchange rate by changing the relative money demand. Note that, prior to the money shock, the $M M$ schedule passes through the origin. Next, both the $G^{\alpha} G^{\alpha}$ and $G^{\beta} G^{\beta}$ schedules are shown as upward-sloping graphs. The depreciation of

Figure 3. Production relocation and effects of monetary expansion.

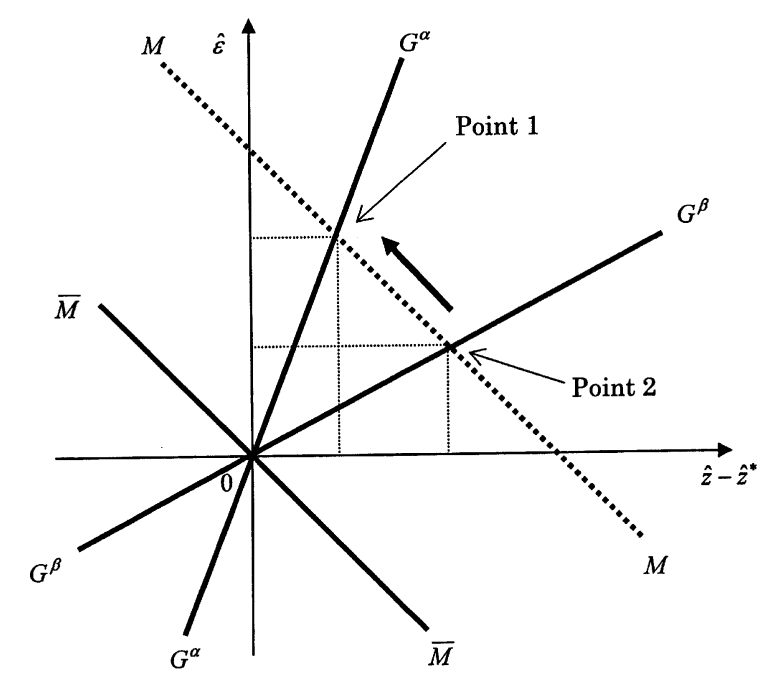


home currency raises relative home output and relative national income; both schedules therefore are drawn as upward-sloping graphs. Moreover, we should note that the slope of the $G^{\alpha} G^{\alpha}$ schedule is steeper than that of $G^{\beta} G^{\beta}$, because $1<\frac{\bar{y}+\theta \bar{y}^{*}}{\bar{y}}$.

In case of $\alpha=\beta$, the money supply shock shifts the short-run equilibrium from the origin to point 2 . On the other hand, it shifts the equilibrium to point 1 in case of $\alpha \neq \beta$. From figure 3, we can find that the magnitude of money shock effect on the exchange rate change is amplified when there has been some production relocation. On the other hand, it on relative home national income must be reduced by advancing production relocation. These results strongly depend on the existence of profit remittance. If the profit remittance doesn't exist in our model $(\theta=0)$, the $G^{\alpha} G^{\alpha}$ schedule must be equal to $G^{\beta} G^{\beta}$. (See $(18 \mathrm{~b}, \mathrm{c})$.) However, as $\alpha$ increases, (hence, $\theta \rightarrow 1$,) the equilibrium point in figure 3 moves to the left along the $M M$ schedule.

Proposition 3: Advancing production relocation amplifies the effect of monetary policy on the exchange rate (terms of trade). On the other hand, it reduces the effect on the relative home income by advancing production relocation.

\section{Conclusions}

This paper examines the effect of production relocation on national economies. Our model is the static version of a famous open economy macroeconomic model, presented by Obstfeld and Rogoff (1995), in the presence of production relocation. From our simple analysis, we can find that the advance of production relocation doesn't necessarily have a contractionary effect on the home economy, and may have an expansive effect, contrary to the conventional wisdom. Moreover, we are also interested in the effects of macroeconomic policy in the world where the production relocation exists. From our analysis, we find that monetary expansion in any country must have expansive effects on the national incomes and must certainly also improve the welfare of all countries. Therefore, we can conclude that monetary policy becomes a "prosper-thyself/prosper-thy-neighbor" policy, and the inference of Obstfeld and Rogoff holds even in a situation in which production relocation exists.

We also examine whether the magnitude of the effects of monetary policy is affected 
by advancing of production relocation. Analysis using the linearized version of our model produces the clear result that the existence of profit remittance, which is accompanied by production relocation, amplifies the effects of monetary expansion on the exchange rate but reduces the policy's effect on the relative home national income. Moreover, advancing production relocation makes this tendency stronger.

\section{Appendix: Robustness of the results}

We have shown in section 3 that the production relocation might not necessarily be contractionary and may even be expansionary to the home (source) country. However, one might guess that this result may critically hinge on the assumption of the predetermined nominal wage. For instance, "is the result of proposition 1 can still hold without the nominal wage rigidity?" To clear the apprehension, we will briefly refer to an extension of the previous analysis and the major revision that follow.

We now introduce the wage determination mechanism of Fender-Yip (1994) into our model. The nominal wage rate, which is taken as a given by the firm, is determined by a union. Each union determines $w_{i}$ to maximize its surplus $v_{i}$. The "surplus" means the difference between what its members get when employed and unemployed.

$$
v_{i}=\left(w_{i}-\bar{w}\right) l_{i}
$$

where $\bar{w}$ is the nominal unemployed benefit in country $\mathrm{H}$. We assume that all unions in both countries solve the same maximization. Considering $l_{i}=c_{i}+c_{i}{ }^{*}$, (3c) and its foreign counterpart, we have the optimal wage level from these maximizations:

$$
w_{i}=\frac{\bar{w}}{\rho}(i \in[\alpha, 1]), w_{i}^{*}=\frac{\bar{w}^{*}}{\rho}(i \in[0, \alpha]) .
$$

Nominal wages are a constant mark-up on unemployment benefits. Therefore, we can find the robustness of our analysis, in spite of an introduction of the wage determination mechanism into our model.

\section{Acknowledgements}

The author is very grateful to Professor Yoshiharu Kikumoto of the University 
of Hyogo and Professor Kouji Aoki of Konan University, and Professor Sadayoshi Takaya of Kansai University, for their valuable comments and encouragement.

Received 5 October 2003, Accepted 2 December 2004

\section{References}

Betts, C., Devereux, M.B. (1996) The Exchange Rate in a Model of Pricing-to-market, European Economic Review, 40, 1007-1021.

Betts, C., Devereux, M.B. (2000) Exchange Rate Dynamics in a Model of Pricing-tomarket, Journal of International Economics, 50, 215-244.

Fender, J., Yip, C.K. (1994) Open Economy Macroeconomics under Imperfect Competition: A Two-country Model, Journal of International Economics, 37, 49-63.

Goldberg, P.K., Knetter, M. (1997) Goods Prices and Exchange Rates: What Have We Learned?, Journal of Economic Literature, 35, 1243-1272.

Markusen, J.R., Maskus, K.E. (2001) General Equilibrium Approaches to the Multinational Firm: A Review of Theory and Evidence, NBER working paper, 8334.

Obstfeld, M., Rogoff, K. (1995) Exchange Rate Dynamics Redux, Journal of Political Economy, 103, 624-660.

Obstfeld, M., Rogoff, K. (1996) Foundations of International Macroeconomics, The MIT Press, Cambridge, MA.

Obstfeld, M., Rogoff, K. (2000) New Directions for Stochastic Open Economy Models, Journal of International Economics, 50, 117-153.

Tille, C. (2001) The Role of Consumption Substitutability in the International Transmission of Monetary Shocks, Journal of International Economics, 53, 421-444. 